Article

\title{
Assessing the Regional Sustainability of the Beijing-Tianjin-Hebei Urban Agglomeration from 2000 to 2015 Using the Human Sustainable Development Index
}

\author{
Shiyin Chen ${ }^{1,2}$, Qingxu Huang $1,3, *(1)$, Ziwen Liu ${ }^{1,3}$, Shiting Meng ${ }^{1,3}$, Dan Yin ${ }^{1,3}$, Lei Zhu ${ }^{1,2}$ \\ and Chunyang $\mathrm{He}^{1,3}$ \\ 1 Center for Human-Environment System Sustainability (CHESS), State Key Laboratory of Earth Surface \\ Processes and Resource Ecology (ESPRE), Beijing Normal University, Beijing 100089, China; \\ shiyinchen@mail.bnu.edu.cn (S.C.); zwliu@mail.bnu.edu.cn (Z.L.); stmeng@mail.bnu.edu.cn (S.M.); \\ yindan@mail.bnu.edu.cn (D.Y.); zhulei@mail.bnu.edu.cn (L.Z.); hcy@bnu.edu.cn (C.H.) \\ 2 Faculty of Geographical Science, Beijing Normal University, Beijing 100089, China \\ 3 School of Natural Resources, Faculty of Geographical Science, Beijing Normal University, \\ Beijing 100089, China \\ * Correspondence: qxhuang@bnu.edu.cn; Tel.: +86-010-58800258
}

Received: 13 May 2019; Accepted: 30 May 2019; Published: 5 June 2019

\begin{abstract}
Sustainability assessment can analyze the challenges of regional development from societal, economic, and environmental dimensions and provide an important baseline for regional planning. Recently, the rapid socio-economic development of the Beijing-Tianjin-Hebei (BTH) urban agglomeration has inflicted great pressure on the regional environment. Therefore, this paper evaluated the sustainability dynamics of the BTH urban agglomeration from 2000 to 2015 at the city scale using the Human Sustainable Development Index (HSDI) and discussed the major drivers of the changes in regional sustainability. The results showed that the overall sustainability of the BTH urban agglomeration increased from 2000 to 2015, with the HSDI increasing by $10 \%$. Among the three dimensions, the economic sustainability indicators grew the fastest, with a growth rate of $42 \%$, while the environmental sustainability indicators declined by $8 \%$. The decline of environmental sustainability played an important role in limiting regional sustainable development. Specifically, the optimization of the energy structure in six cities, e.g., Tangshan, Langfang and Cangzhou, was relatively weaker than that in the remaining seven cities. In the future, the BTH urban agglomeration must further optimize the energy structure to build a resource-saving and environmentally friendly society.
\end{abstract}

Keywords: sustainability assessment; Human Sustainable Development Index; energy structure; urban agglomeration; urban sustainability

\section{Introduction}

The quantitative assessment of regional sustainability can evaluate the sustainability of complex nature-society systems at a variety of temporal and spatial scales [1,2]. These assessments can help policymakers to understand the complex relationship among various components of regional sustainable development and provide effective guidance for policy-making [3,4]. The sustainability assessment of a region needs to not only focus on the overall sustainability state, but also to examine the differences in social, economic, and ecological development within the region [5]. This dual focus will contribute to future regional planning and decision-making, facilitating the further exploration 
of potential factors that affect regional sustainable development [6,7]. Two perspectives existed in previous studies, strong and weak sustainability $[3,8]$. Strong sustainability assumes that socioeconomic development (or human-made capital) and environmental integrity (or natural capital) are not alternative [9]. Replacement with human-made capital can be difficult when critical natural capital is damaged; that is, economic development cannot be achieved at the cost of environmental damage [10]. Weak sustainability assumes that human-made capital and natural capital can be substituted, which supports the idea that economic development at the cost of environmental degradation is also sustainable $[9,11]$. However, weak sustainability is unsustainable in the long term $[2,6]$.

A large number of indicators and indicator systems for sustainability assessment (Table 1) have emerged since the first Earth Summit in 1992, which called for the development of sustainability assessment methods $[3,12]$. Some methods focus one or two dimensions of sustainability, such as the Human Development Index (HDI) developed by the United Nations Development Programme [13], the Happy Planet Index (HPI) developed by the New Economics Foundation [14], and the Green City Index (GCI), which was developed by the Economic Intelligence Unit and Siemens [15]. Meanwhile, some methods include the above three dimensions, such as the Human Sustainable Development Index (HSDI) developed by Togtokh and Gaffney [16], the City Development Index (CDI), which was developed by the United Nations Human Settlements Programme [17], and the Sustainable Society Index (SSI) developed by the Sustainable Society Foundation [18]. These indicators and indicator systems have been accepted as a tool to guide mankind towards the sustainable development goals, because their calculations are relatively simple $[2,19]$.

Researchers have evaluated the sustainability of the Beijing-Tianjin-Hebei (BTH) urban agglomeration by using different indicators and indicator systems from the dimensions of society, economy, and the environment. In terms of social and economic dimensions, Yang et al. studied the differences in social-economic development among different provinces in China in 2003 and divided the country into four tiers that are based on the human development index (HDI) [20]. They found that Beijing and Tianjin were in the first tier with the highest performance, while Hebei Province was in the third tier with a lower performance. Theng et al. calculated and compared the smart city index of 32 major cities in China in 2011, and found that, in the overall scores of smart city, Beijing and Tianjin ranked fourth and 12th, respectively, while Shijiazhuang, the capital of Hebei province, ranked 29th, out of 32 cities [21]. In terms of the environment dimension, Yu et al. divided China into eight major economic zones, and then calculated and mapped the spatial distributions of the green GDP from 1990 to 2015. The results indicated that the Northern Coastal Economic Zone, which contains Beijing, Tianjin, Hebei, and Shandong, had the highest increase rates of green GDP in all eight zones and the contribution of economic development to green GDP dominated [22]. Sun et al. established the indicator system of green development, analyzed the evolution process of green development, and divided the green development level of 30 Chinese provinces and cities into four levels. Beijing and Tianjin had the highest scores for sustaining input, and Hebei Province was at the lowest level, with a low sustaining input score [23]. Gao et al. studied the status of regional freshwater sustainability in the BTH region by constructing the freshwater ecosystem service footprint model and found that most of the regions in the BTH urban agglomeration were in a sustainable development status, except in the regions around Beijing [24]. Peng et al. divided Beijing into four zones according to the utilization of natural capital. They found that only the second zone did well in balancing efficiency, equity, and ecology, while the other three zones should, in future development, separately emphasize these three aspects [25]. In summary, most of the studies have focused on only the socio-economic dimension or the environmental dimension, and have not fully covered the three dimensions of sustainable development. In addition, due to the large demand for data, few studies have evaluated sustainability at the city scale in urban agglomeration [26]. 
Table 1. Widely used sustainability assessment indices.

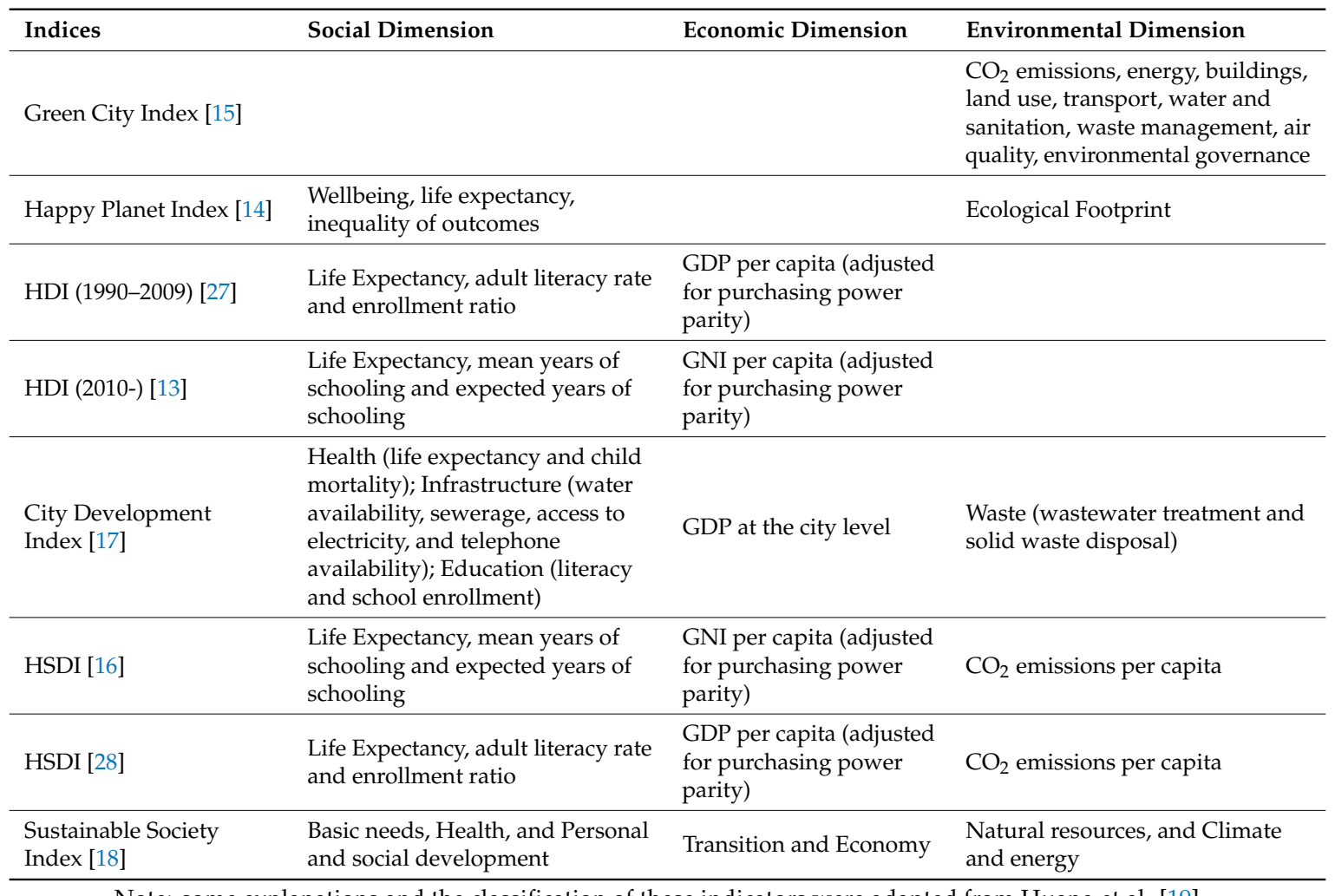

Note: some explanations and the classification of these indicators were adapted from Huang et al. [19].

The Human Sustainable Development Index (HSDI) provides a new way to comprehensively assess the sustainability of the BTH urban agglomeration. First, the HSDI adds the per capita $\mathrm{CO}_{2}$ emissions on the basis of the HDI, which includes environmental factors in the sustainability assessment. This inclusion enables the HSDI to encompass the "three dimensions" of sustainable development, i.e., the environmental, economic, and social dimensions, and it facilitates a comprehensive assessment of regional sustainable development $[28,29]$. Second, in terms of calculating the HSDI, the demand for data is relatively small and the acquisition of data is relatively easy. Most of the data required to calculate the HSDI can be obtained from the statistical data released by government and international organizations, which lays a foundation for a sustainability assessment at the city scale.

This paper aims to evaluate the regional sustainability of the BTH urban agglomeration from multiple scales for the last 15 years. First, the HSDI values of BTH urban agglomeration were calculated at the provincial and city scales in 2000 and 2015. Subsequently, the dynamics of the HSDI in the BTH urban agglomeration was examined in the past 15 years using the changes in the HSDI and cluster analysis. Finally, the paper discusses the main causes of sustainability changes in the BTH urban agglomeration and provides suggestions for regional sustainable development in the future.

\section{Study Area and Data}

\subsection{Study Area}

The BTH urban agglomeration is located between $113.27^{\circ} \mathrm{E}$ and $119.50^{\circ} \mathrm{E}$ and between $36.05^{\circ} \mathrm{N}$ and $42.40^{\circ} \mathrm{N}$ (Figure 1). It consists of Beijing, Tianjin, and eleven prefectural cities in the neighboring Hebei Province. It is one of the three major national-level urban agglomerations in China [30]. In 2017, the population of the BTH urban agglomeration accounted for $8 \%$ of the country's total population, creating a regional GDP of 8058 billion yuan, which is more than one-tenth of the overall GDP of China [31]. The 13th Five-year Plan for National Economic and Social Development of the People's Republic of China sets the goal of building the BTH urban agglomeration into a world-class urban agglomeration, 
with Beijing as the core. In the future, the BTH urban agglomeration will play an important role in establishing national competitiveness, coping with global competition [29], improving the prosperity of the Bohai-rim region, and promoting the development of the northern hinterland. However, during the process of rapid economic development, the BTH urban agglomeration still encountered problems, such as large industrial gas emissions and urban effluent discharge [32], declining in biological carrying capacity along with socio-economic development [33], and an imbalance in regional development [29].

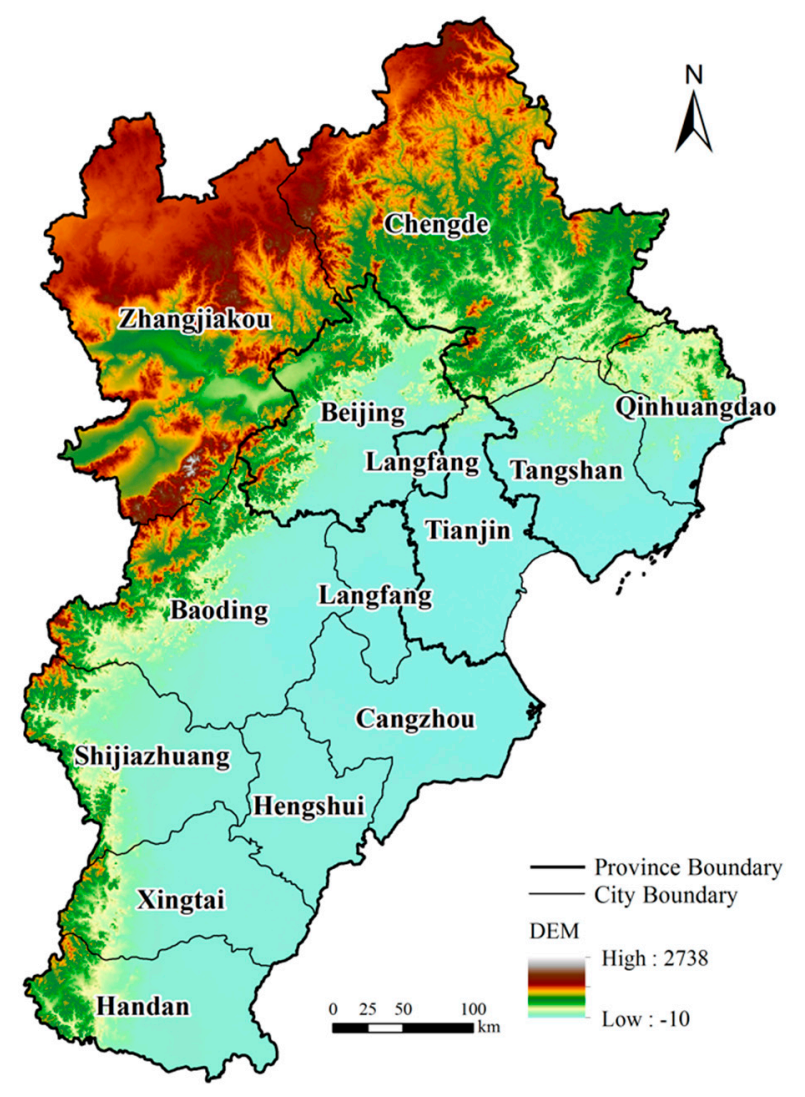

Figure 1. The Beijing-Tianjin-Hebei urban agglomeration.

\subsection{Data}

The socio-economic data that were used in this paper include the per capita GDP, the proportion of illiterate people aged 15 and over, the number of primary, secondary and high school students, and the age structure in each region. The above data were collected from the China City Statistical Yearbook, the Beijing Statistical Yearbook, the Tianjin Statistical Yearbook, and the Hebei Economic Yearbook in 2001 and 2016 [34-41]. China's implied purchasing power parity conversion rates in 2000 and 2015 were from the World Economic Outlook data website (http://www.econstats.com/weo/V013.htm), which was released by the International Monetary Fund (IMF).

Second, the provincial energy balance tables (EBTs) were all drawn from the China Energy Statistics Yearbook in 2001 and 2016 [42,43]. River, highway, railway, prefecture-level city, and county-center vector data with a scale of 1:4,000,000 were from the National Geographic information public service platform (http://service.tianditu.gov.cn/).

\section{Methods}

\subsection{Calculating the HSDI}

The selection of variables for calculating the sustainability indicator or indicator set is strongly limited by data availability and regional context [44]. The variable selected in this study covers all 
three dimensions of sustainability in order to make the assessment comprehensive and repeatable, while we also considered the difficulty of data acquisition of Chinese prefecture-level cities and used the widely recognized urban indicators [19]. Specifically, we chose the HSDI for the following three reasons. First, HSDI is developed on the basis of HDI, which has become a standard and widely reported indicator in many formal reports and academic publications [3]. Second, HSDI provides a sustainability assessment in the environmental dimension by using per capita $\mathrm{CO}_{2}$ emission, which is a simple but quantifiable indicator for different countries and cities [45]. Third, the variables and data for calculating HSDI is accessible at the prefecture-level city level in China when compared to other sustainability assessment indices (Table 1).

Based on the method of the HSDI calculation that was proposed by Togtokh and Gaffney, as well as the methods of Bravo et al. and Li et al., this study quantified the HSDI at the city scale in 2000 and $2015[16,28,46]$. The HSDI used four different sets of data, including life expectancy at birth, education level, per capita GDP, and per capita $\mathrm{CO}_{2}$ emissions. The specific calculation formula is as follows:

$$
H S D I=\sqrt[4]{L E I \times E I \times G D P I \times E M I},
$$

where $L E I$ and $E I$ are the health indicator and education indicator representing social sustainability, and GDPI is a material living standard indicator representing economic sustainability. LEI, EI and GDPI are calculated in the same way as the HDI index developed by the UNDP [13]. The per capita $\mathrm{CO}_{2}$ emission index, $E M I$, is used to represent environmental sustainability

Specifically, the health indicator $L E I$ focuses on life expectancy at birth (LE), which is derived from data from the fifth and sixth national censuses. The data from 2010 were used in this study to replace the data from 2015, and the average life expectancy of Hebei Province was used for all prefecture-level cities in Hebei due to the limitation of data availability. The calculation formula is as follows:

$$
L E I=\frac{L E-25}{85-25}
$$

where $E I$ quantifies the adult literacy rate $(A L)$ and comprehensive gross enrollment rate $(E R)$ of primary, secondary, and higher education. $A L$ is the proportion of people aged 15 and above who are illiterate. The $E R$ is obtained by dividing the total number of students in primary schools, middle schools, and universities by the number of individuals aged 5-24 in the school-age population. The calculation formula is as follows:

$$
E I=\frac{2}{3} \times A L+\frac{1}{3} \times E R,
$$

where GDPI measures China's GDP per capita adjusted through purchasing power parity, that is, $G D P p c$, from the economic perspective. GDPpc is calculated by dividing the GDP per capita by the implied purchasing power parity conversion rate that is published by the IMF. The calculation formula is as follows:

$$
G D P I=\frac{\log _{2} G D P p c-\log _{2} 100}{\log _{2} 40,000-\log _{2} 100}
$$

where $E M I$ reflects the environmental sustainability via per capita $\mathrm{CO}_{2}$ emissions $\left(E M_{\mathrm{CO} 2} p c\right) . E M_{\mathrm{CO} 2} p c$ is calculated by dividing the total $\mathrm{CO}_{2}$ emissions of the region by the population of the region. The calculation formulas of $E M I$ and $E M_{\mathrm{CO} 2} p c$ are as follows:

$$
E M I=1-\frac{E M_{\mathrm{CO} 2 \mathrm{pc}}}{63.18 \times \text { Population }}
$$

where $E M_{\mathrm{CO} 2}$ is the total regional $\mathrm{CO}_{2}$ emissions. This value is calculated following the 2006 IPCC Guidelines for National Greenhouse Gas Inventories, which involves adopting the energy consumption in the EBTs and the default emission factors for energy activities from the Greenhouse Gas Accounting 
Tool for Chinese Cities (Pilot Version 1.0), which was released by the World Resources Institute (WRI) (Washington, DC, USA) $[47,48]$. The specific formula is as follows:

$$
E M_{\mathrm{CO} 2}=\Sigma\left(\text { FC City } \mathrm{y}_{i} \times \text { Emission }_{\text {Factor }}\right),
$$

where $E M_{C O 2}$ is the $\mathrm{CO}_{2}$ emissions that are generated by energy consumption. FC City is the consumption of the $i$ th energy in the provincial area $\left(10^{4} \mathrm{t}\right)$, and Emission Factor ${ }_{i}$ is the $\mathrm{CO}_{2}$ emission factor of the $i$ th energy fuel $\left(10^{4} \mathrm{tCO}^{2} / 10^{4} \mathrm{t}\right)$.

Due to the lack of EBTs for all prefecture-level cities in Hebei Province, the FC City $y_{i}$ of energy consumption of the $i$ th prefecture-level cities in Hebei Province cannot be directly obtained. This study referred to the method that was proposed by Jing et al. and proportionately allocated the provincial energy consumption of all types to prefecture-level cities [49].

$$
\text { FC City } \text { i }_{i}=\Sigma\left(\text { Fuel Consumption }{ }_{i, j} \times a_{j}\right),
$$

where Fuel Consumption $i, j$ is the total consumption of the $j$ th item of the $i$ th energy in the provincial EBT $\left(10^{4} \mathrm{t}\right) . a_{j}$ is the proportion of energy consumption distribution of the $j$ th item in a prefecture-level city and it can be calculated as

$$
a_{j}=\frac{I \text { city }_{k, j}}{\text { Iprovince }}
$$

where Icity $y_{k}$ is the distribution indicator value of the $j$ th project in the $k$ th city, and Iprovince is the distribution indicator value of the province where the city is located. Table 2 shows the selected results of the distribution indicators. The distribution principle referred to the work by Jing et al., and this approach makes it easy to obtain the selected distribution indicators that fully represent the energy consumption of the item [49].

Table 2. The energy consumption distribution indicators of different items in the energy balance tables (EBTs).

\begin{tabular}{lll}
\hline Item & Distribution Indicators & Unit \\
\hline Transformation, Industry Final & Output value of industry & $10^{8}$ yuan \\
Consumption (Non-Energy Use) & Social electricity consumption & $10^{8} \mathrm{KWH}$ \\
Loss & Output value of agriculture, forestry, & $10^{8}$ yuan \\
Agriculture, Forestry, Animal & animal husbandry and fishery & $10^{8}$ yuan \\
Husbandry and Fishery & Output value of construction & $10^{4}$ people, $10^{4}$ tons, $10^{8}$ yuan \\
Construction & Transportation and postal services & $10^{8}$ yuan \\
Transport, Storage and Post & Output value of wholesale, retail trade & $10^{8}$ yuan \\
Wholesale, Retail Trade and Hotels, & and hotels, restaurants & $10^{4}$ people \\
Restaurants & Output value of service industry & $10^{4}$ people \\
Others & Urban population & Rural population \\
Urban Residential Consumption & & \\
Rural Residential Consumption & . & \\
\hline
\end{tabular}

\subsection{Cluster Analysis}

We further analyzed the difference in sustainability in the region using the hierarchical cluster analysis. Previous studies suggest that multiple methods can be used to group the regions into clusters, and statistical tests should validate the clustering results [50,51]. Therefore, we conducted the cluster analysis in the following three steps. In the first step, the distance measure was the squared Euclidean distance, which is the most commonly used distance measure for continuous variables and it can obtain differences between the mean profiles of clusters [50,52]. Afterwards, the average linkage between groups was used to determine the number of clusters. Finally, the clustering results were further verified by the non-parametric tests.

In this paper, we conducted two cluster analyses on the sustainable development status and the dynamics of the urban agglomeration, respectively. Specifically, the HSDI, LEI, EI, GDPI, and 
EMI of the BTH urban agglomeration in 2015 were selected to classify the sustainable status in 2015. In addition, we classified the categories of sustainable change by using the changes in the EMI and GDPI from 2000 to 2015.

Since there are only 13 cities, we chose the non-parametric test to validate the cluster results, because it does not need to meet the assumption of normal distribution of samples [53]. Specially, as the first cluster analysis divided the 13 cities into three categories based on the sustainability status in 2015, the Kruskal-Wallis $\mathrm{H}$ test is used to validate the difference. As the second cluster analysis divided the cities into two categories based on the EMI changes and GDPI changes from 2000 to 2015, the Mann-Whitney U test was used to identify whether there were significant differences between the two categories of cities from 2000 to 2015. The three-step cluster analysis was performed while using SPSS 24.0 software (IBM, New York, USA) [54].

\subsection{Aanalyzing the Correlation among between Environmental Indicator and HSDI}

To explore the contribution of the change in environmental dimension of sustainability to the integrated indicator, HSDI, we conducted the Person correction between EMI and HSDI among the 13 cities in the BTH urban agglomeration. The calculation formula is as follows:

$$
r=\frac{\sum_{i=1}^{n}\left(x_{i}-\bar{x}\right)\left(y_{i}-\bar{y}\right)}{\sqrt{\sum_{i=1}^{n}\left(x_{i}-\bar{x}\right)^{2} \sum_{i=1}^{n}\left(y_{i}-\bar{y}\right)^{2}}}
$$

where $r$ is the Pearson correlation coefficient; $i$ is the $i$ th city, ranging from 1 to $13 ; n$ is the total number of cities; $x_{i}$ is the change of HSDI of the $i$ th city; $y_{i}$ is the change of EMI of the $i$ th city; and, $\bar{x}$ and $\bar{y}$ are the mean change of HSDI and mean change of EMI, respectively. The calculation of $r$ and followed t-test are carried out in SPSS 24.0 software [54].

\section{Results}

\subsection{Regional Sustainable Development Status of the BTH Urban Agglomeration in 2015}

The regional sustainability of the BTH urban agglomeration was above the average level. The HSDI of the BTH urban agglomeration was 0.85 in 2015, a value that was higher than the average HSDI of China in 2010, which was 0.83 [28]. Within the urban agglomeration, there was a large disparity in the HSDI among the Beijing, Tianjin, and Hebei provinces, and smaller differences were found among prefecture-level cities in Hebei Province. Beijing had the highest HSDI of 0.89 (Figure 2), which was $5.06 \%$ higher than that of Tianjin and $7.86 \%$ higher than that of Hebei Province. The HSDI of all prefecture-level cities in Hebei Province was greater than 0.80, and the discrepancies between prefecture-level cities were relatively small. The highest HSDI of 0.84 was in Qinhuangdao, which was only $3.58 \%$ higher than that in Hengshui.

Cluster analysis showed that the 13 cities in the BTH urban agglomeration in 2015 could be classified into three categories (Figure 3). The Kruskal-Wallis $\mathrm{H}$ test supported that the clustering results were reliable (Table 3). In terms of LEI, GDPI, EMI, and HSDI, the three categories of cities were significantly different. The differences in LEI and GDPI were significant at the 0.01 level, and the $p$ values of EMI and HSDI were less than 0.05 . In terms of $E I$, the $p$ value was 0.077 , which suggested that it passed the significance test at the 0.1 level. 


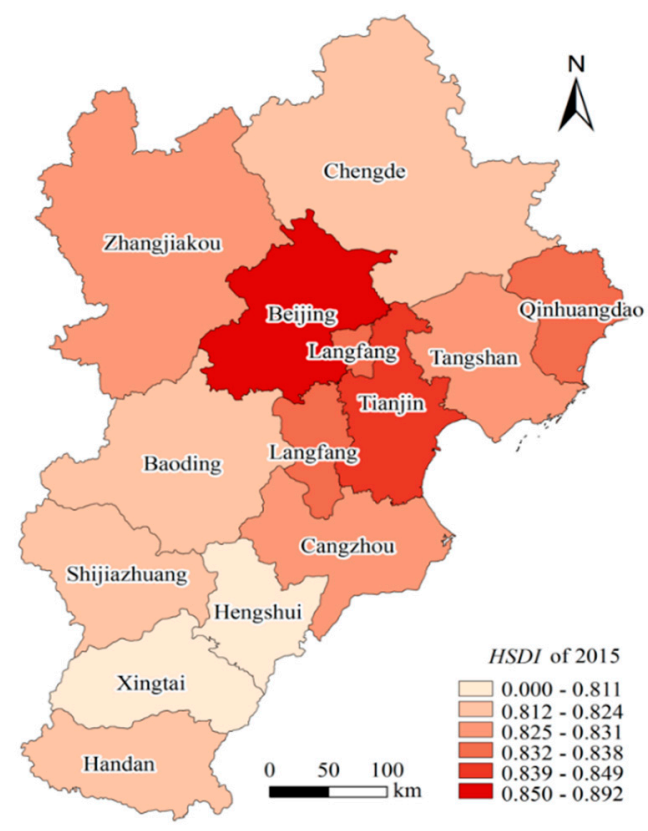

Figure 2. The sustainability level of the Beijing-Tianjin-Hebei (BTH) urban agglomeration in 2015. (Note: the HSDI value was classified by the natural break method).

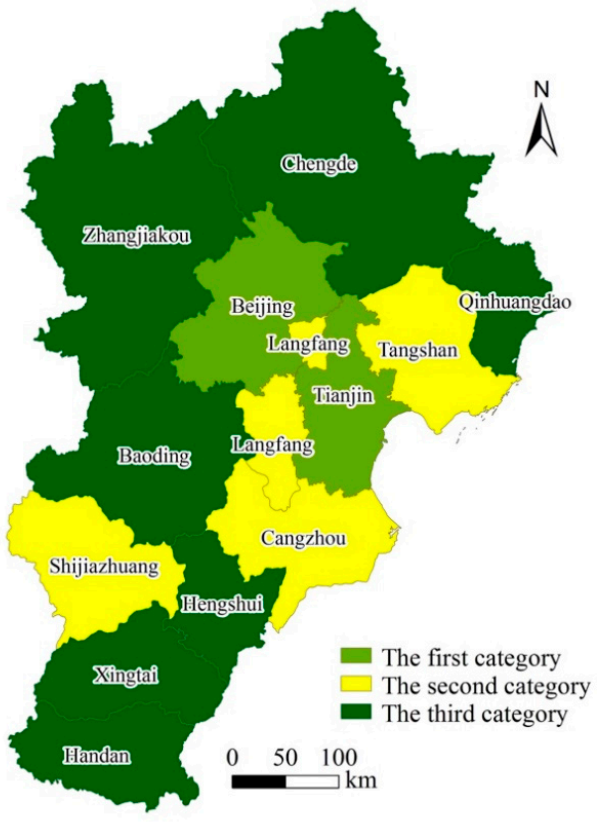

(a)

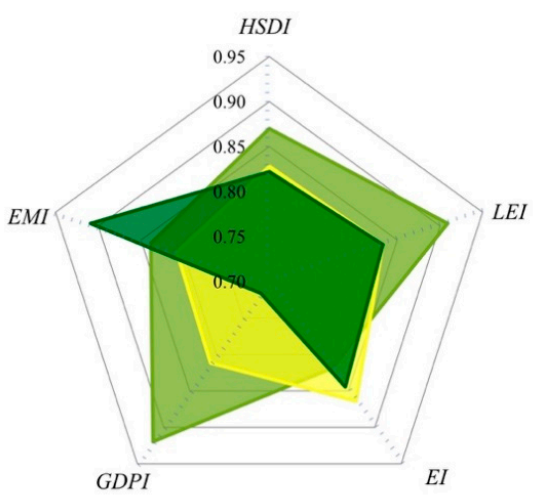

(b)

Figure 3. Sustainability classification of the BTH urban agglomeration in 2015. (a) The spatial distribution of the three categories of cities; and, (b) The characteristics of the sustainable indicators of the three categories of cities.

Table 3. The Kruskal-Wallis H test results for the five indicators used in the HSDI among the 13 cities in the BTH urban agglomeration.

\begin{tabular}{llllll}
\hline & LEI & EI & GDPI & EMI & HSDI \\
\hline$\chi^{2}$ & 11.917 & 5.129 & 9.791 & 8.323 & 6 \\
$d f$ & 2 & 2 & 2 & 2 & 2 \\
$p$ & 0.003 & 0.077 & 0.007 & 0.016 & 0.050 \\
\hline
\end{tabular}


Among the three categories of cities, the first category of cities, which included Beijing and Tianjin, had the highest level of overall sustainability, economic sustainability, and healthy sustainability. The average HSDI, GDPI and LEI values for the cities in the first category were $0.87,0.92$ and 0.91 , respectively. In terms of environmental sustainability, cities in the first category were at an intermediate level, and the EMI of these cities was 0.839 , which was slightly higher than that of cities in the second category (i.e., 0.81) and smaller than that of cities in the third category (i.e., 0.91). For educational sustainability, the cities in the first category showed the lowest $E I$, which was 0.82 .

The second category (i.e., Shijiazhuang, Langfang, Cangzhou and Tangshan) included the cities with an intermediate overall sustainability level and a low environmental sustainability level. The average HSDI of these cities was 0.83 . The environmental sustainability level of this category was the lowest among the three categories, and the EMI was only 0.81 , which was $12.50 \%$ lower than that of the third category. In terms of the educational sustainability level, the second category of cities had the highest $E I$, which was 0.86 .

The third category consisted of the cities with a high level of environmental sustainability but low levels of overall sustainability and economic sustainability. Those cites included Qinhuangdao, Chengde, Handan, Hengshui, Xingtai, Zhangjiakou, and Baoding, in which the highest EMI was 0.91, the lowest HSDI was 0.82. Among these cities, the GDPI was significantly different from that of the other two categories. The GDPI in the third category was $22.17 \%$ and $11.74 \%$ lower than those in the first and second categories, respectively.

\subsection{Regional Sustainable Development Dynamics of the BTH Urban Agglomeration from 2000 to 2015}

From 2000 to 2015, the regional sustainability of the BTH urban agglomeration showed an overall increasing trend (Figure 4). The HSDI increased from 0.772 to 0.849 , with an increase of 0.078 and a growth rate of $10.1 \%$. From the perspective of the three dimensions of sustainability, the levels of economic and social sustainability of BTH urban agglomeration increased, and the level of environmental sustainability decreased from 2000 to 2015 . The GDPI, which represented economic sustainability, increased from 0.584 to 0.830 , with an increase of 0.246 and a growth rate of $42.0 \%$. The $L E I$ and $E I$, representing social sustainability, increased from 0.804 and 0.807 to 0.859 and 0.844 , with growth rates of $6.8 \%$ and $4.6 \%$, respectively. The $E M I$, which represents environmental sustainability, decreased from 0.935 to 0.864 , with a decrease of 0.071 and a change rate of $-7.6 \%$. Among the changes in the three dimensions, the change rate of economic sustainability was the largest. The variation in GDPI was 5.00, 6.25, and 3.57 times the variation in $L E I, E I$, and EMI, respectively.

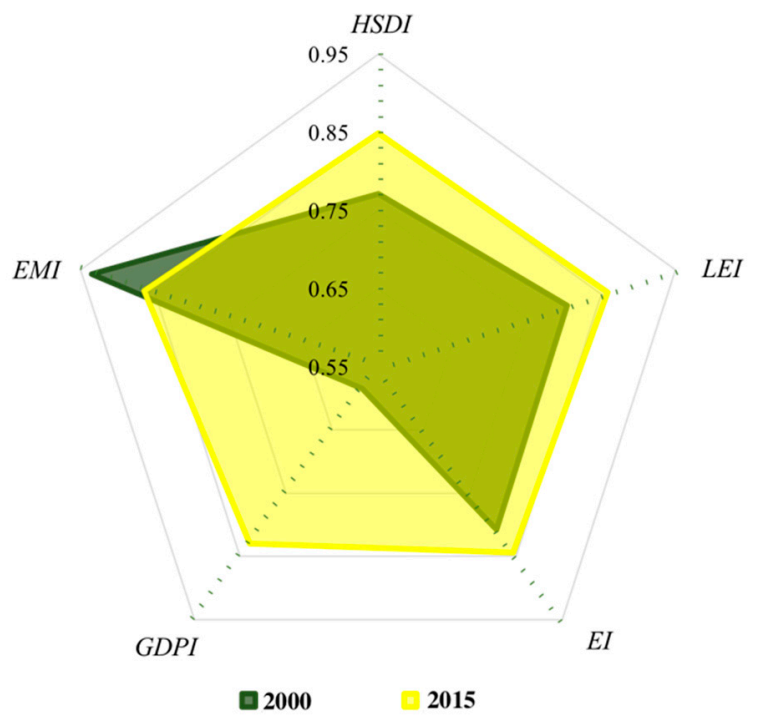

Figure 4. The changes in the HSDI of the BTH urban agglomeration from 2000 to 2015. 
The 13 cities in the BTH urban agglomeration can be divided into two categories, according to the changes of EMI and GDPI (Table 4, Figure 5). The Mann-Whitney U test results showed that the clustering results were also reliable (Table 5). In terms of the changes of GDPI and EMI, the two categories of cities are significantly different, and they passed the significance test at the 0.01 level.

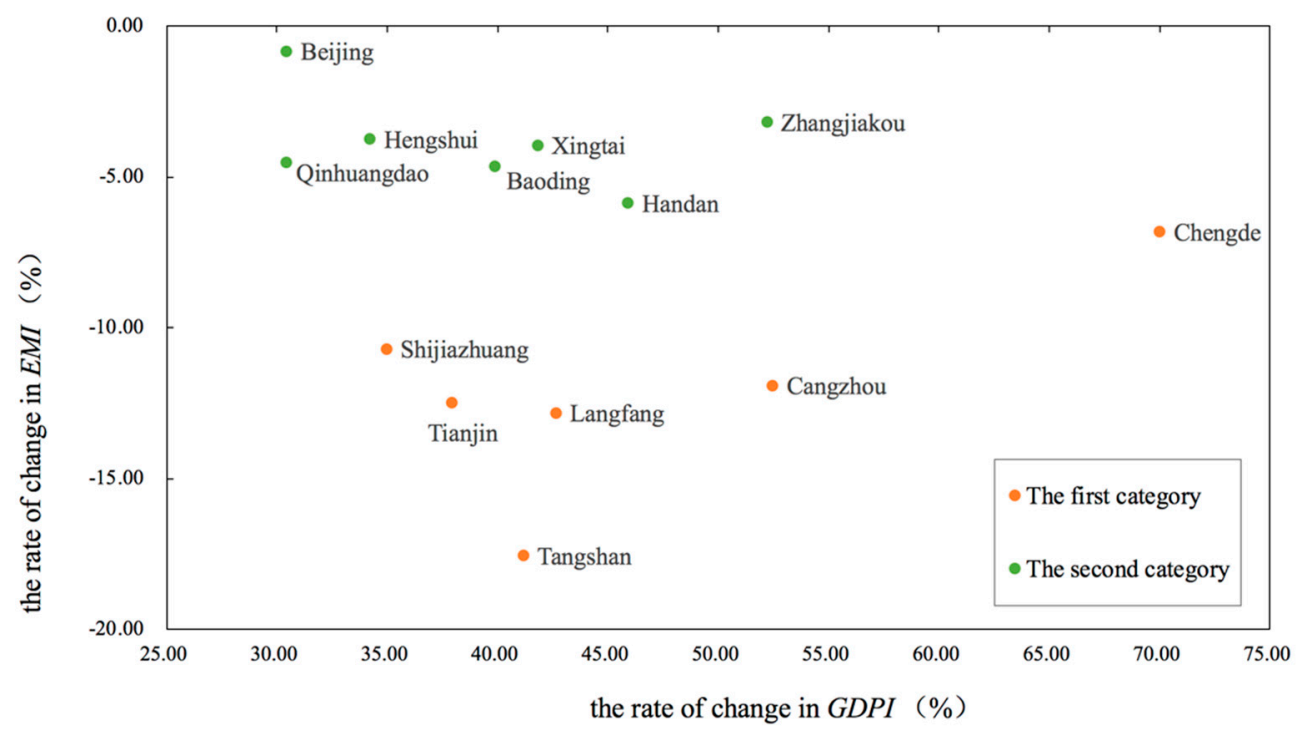

Figure 5. The change rates of economic sustainability indicator (GDPI) and environmental sustainability indicator (EMI) for the BTH urban agglomeration from 2000 to 2015.

Table 4. Changes in the sustainability of the Beijing-Tianjin-Hebei urban agglomeration at the city scale from 2000 to 2015 .

\begin{tabular}{|c|c|c|c|c|c|c|}
\hline Category & Region & $\begin{array}{l}\text { Changes of } \\
L E I\end{array}$ & $\begin{array}{l}\text { Changes of } \\
E I\end{array}$ & $\begin{array}{l}\text { Changes of } \\
\text { GDPI }\end{array}$ & $\begin{array}{l}\text { Changes of } \\
\text { EMI }\end{array}$ & $\begin{array}{l}\text { Changes of } \\
\text { HSDI }\end{array}$ \\
\hline \multirow{7}{*}{ First } & Chengde & 0.040 & 0.038 & 0.308 & -0.066 & 0.107 \\
\hline & Cangzhou & 0.040 & 0.064 & 0.266 & -0.114 & 0.083 \\
\hline & Langfang & 0.040 & 0.051 & 0.241 & -0.122 & 0.066 \\
\hline & Tianjin & 0.066 & 0.017 & 0.253 & -0.111 & 0.059 \\
\hline & Shijiazhuang & 0.040 & 0.041 & 0.206 & -0.097 & 0.057 \\
\hline & Tangshan & 0.040 & 0.065 & 0.253 & -0.159 & 0.056 \\
\hline & Average & 0.045 & 0.046 & 0.255 & -0.111 & 0.071 \\
\hline \multirow{8}{*}{ Second } & Zhangjiakou & 0.040 & 0.077 & 0.244 & -0.030 & 0.103 \\
\hline & Beijing & 0.068 & 0.055 & 0.214 & -0.007 & 0.085 \\
\hline & Handan & 0.040 & 0.043 & 0.228 & -0.056 & 0.082 \\
\hline & Xingtai & 0.040 & 0.041 & 0.198 & -0.038 & 0.079 \\
\hline & Baoding & 0.040 & 0.057 & 0.200 & -0.045 & 0.079 \\
\hline & Qinhuangdao & 0.040 & 0.066 & 0.177 & -0.042 & 0.070 \\
\hline & Hengshui & 0.040 & 0.001 & 0.177 & -0.035 & 0.060 \\
\hline & Average & 0.044 & 0.048 & 0.205 & -0.036 & 0.080 \\
\hline
\end{tabular}

Note: variables in this table have no units.

Table 5. The Mann-Whitney U test results for the changes in sustainability among the 13 cities in the BTH urban agglomeration.

\begin{tabular}{lll}
\hline & Changes of GDPI & Changes of EMI \\
\hline$Z$ & -2.589 & -3.000 \\
$p$ & 0.008 & 0.001 \\
\hline
\end{tabular}

The first category included cities with rapid growth in economic sustainability and a salient decline in environmental sustainability; these cities included Tianjin, Shijiazhuang, Tangshan, Chengde, 
Cangzhou, and Langfang. The average change in the GDPI (which represents economic sustainability) of such cities was 0.255 , with an average increase of $45.1 \%$. The EMI, which represents environmental sustainability, decreased by 0.111 , which was a $12.0 \%$ decline. Among them, Tangshan is an example of a city that had relatively slow economic development as environmental sustainability declined. From 2000 to 2015, the economic sustainability growth of Tangshan only ranked seventh in the BTH urban agglomeration, but its environmental sustainability exhibited the greatest decline. During 2000-2015, the GDPI in Tangshan increased by $41.1 \%$, which was smaller than the overall change in GDPI in Hebei Province (41.8\%) and the overall growth of the GDPI in the BTH urban agglomeration $(42.0 \%)$. Meanwhile, the reduction rate of the EMI in Tangshan was the largest among the 13 cities in the BTH urban agglomeration, accounting for $17.5 \%$, which was 2.32 times the value of the EMI reduction rate $(7.6 \%)$ in the $\mathrm{BTH}$ urban agglomeration.

The second category of cities has a low degree of environmental degradation with economic development. The cities included Beijing, Qinhuangdao, Hengshui, Baoding, Xingtai, Handan, and Zhangiiakou. These cities had a small decline in the EMI as the GDPI increased. Beijing and Zhangjiakou are examples of cities with rapid economic growth and a low degree of environmental degradation. Among them, Beijing had the smallest degree of environmental deterioration with economic growth. The EMI in Beijing decreased by only $0.8 \%$ between 2000 and 2015, which was much lower than the overall EMI declining rate of $7.6 \%$ in the BTH urban agglomeration; the value for Beijing also represented the best value in the BTH urban agglomeration. From 2000 to 2015, the growth rate of GDPI in Zhangjiakou was 52.2\%, ranking third among the 13 cities in the BTH urban agglomeration, and the $E M I$ reduction rate was $3.2 \%$, being second only to Beijing.

\subsection{The Correlation between Evnrionmental Sustainability and HSDI}

The decline of environmental sustainability in the BTH urban agglomeration has played an important role in inhibiting regional sustainable development (Figure 6). The changes in the regional EMI were positively correlated with the changes in the HSDI, with a Pearson correlation coefficient of $0.50(p<0.1)$. This result implied that the cities with a higher degree of decline in environmental sustainability in this urban agglomeration were accompanied by a smaller increase in overall sustainability. Additionally, the Pearson correlation coefficients between the increase of the HSDI and the increase of the LEI, EI and GDPI were $0.10(p=0.739), 0.42(p=0.155)$, and 0.45 $(p=0.126)$, respectively. The result suggested that an increase in social or economic sustainability in the region did not necessarily lead to an increase in overall sustainability.

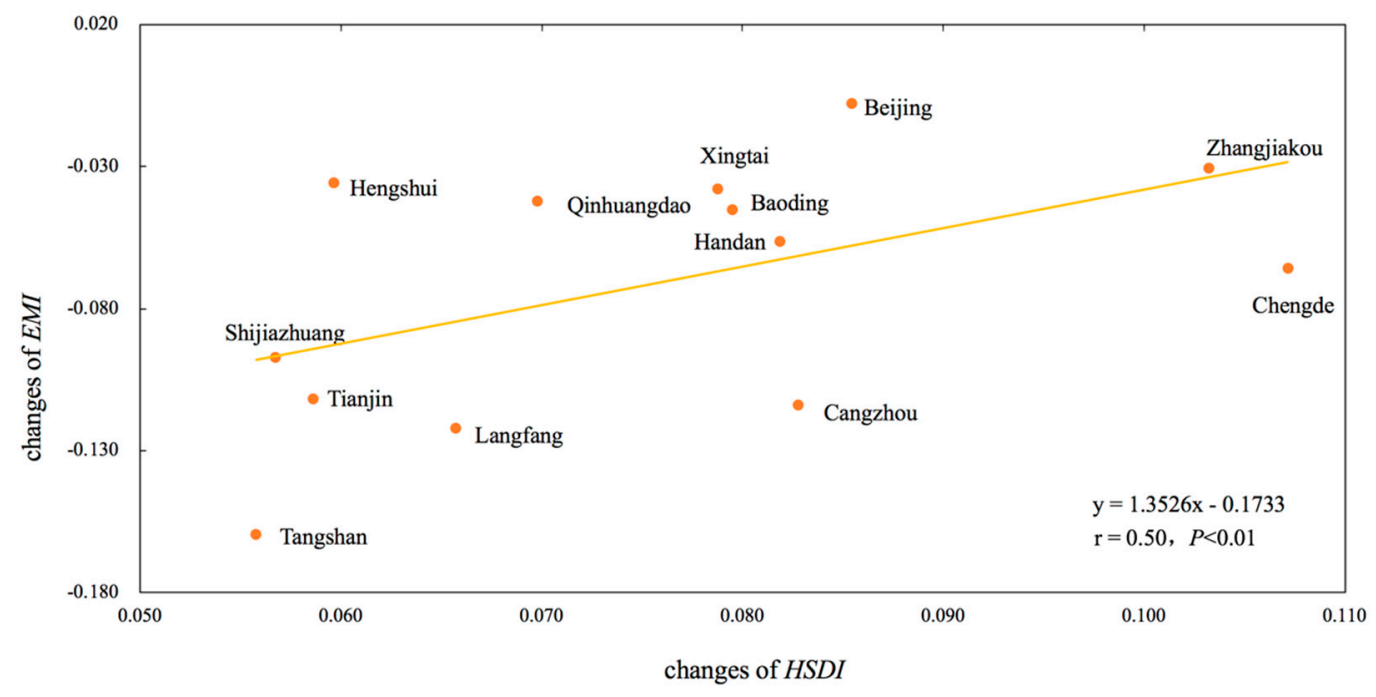

Figure 6. The relationship between the changes in the HSDI and EMI of the Beijing-Tianjin-Hebei urban agglomeration. 
Among the 13 cities in the BTH urban agglomeration, Tangshan was the representative city of the regional sustainable development restricted by the decline in environmental sustainability. Tangshan had the smallest increase in overall sustainability and the largest decrease in environmental sustainability. From 2000 to 2015, the HSDI of Tangshan increased by 0.056 , which was the lowest rate of increase among all cities. The EMI reduction in Tangshan was the greatest, with a decrease of 0.159 . In contrast, Beijing and Zhangiiakou were representative cities in which the decline of environmental sustainability had less impact on regional sustainable development. The overall sustainability of these cities significantly increased, while the environmental sustainability decreased slightly. From 2000 to 2015 , the increase of the HSDI in Beijing was relatively large, with an increase of 0.085, ranking the third in the BTH urban agglomeration. Meanwhile, its EMI reduction was the smallest among the 13 cities in the BTH urban agglomeration, decreasing by only 0.007. From 2000 to 2015, the HSDI in Zhangjiakou increased by 0.103 , ranking the second in the BTH urban agglomeration. The reduction of environmental sustainability was small and the $E M I$ decreased by 0.030 , a value that was only higher than that of Beijing.

\section{Discussion}

\subsection{Optimization of Energy Structure Played an Important Role in Urban Sustainability Change}

We further analyzed the changes in the energy structure at the city scale to explain the changes in the environmental sustainability indicator (EMI) to understand the restricting effect of environmental sustainability changes on regional overall sustainability. Specifically, we investigated the changes in the proportions of three major fossil energy consumptions, i.e., coal, oil, and natural gas, at the city scale [55]. The reduced coal consumption and increased oil and gas consumption were beneficial for reducing $\mathrm{CO}_{2}$ emissions.

The results showed that the fossil energy structure of the BTH urban agglomeration was optimized from 2000 to 2015. During this period, the $\mathrm{CO}_{2}$ emissions that were generated by coal use in the BTH urban agglomeration accounted for a major proportion of the total $\mathrm{CO}_{2}$ emissions and showed a downward trend. The share of $\mathrm{CO}_{2}$ emissions from oil and gas use has increased overall. Specifically, the proportion of $\mathrm{CO}_{2}$ emissions that were generated by coal use in the BTH urban agglomeration was $88.7 \%$ in 2000 and $81.8 \%$ in 2015, representing a decrease of $6.9 \%$. Meanwhile, the share of $\mathrm{CO}_{2}$ emissions from oil use increased from $10.1 \%$ to $11.4 \%$, i.e., an increase of $1.2 \%$. The share of natural gas increased from $6.8 \%$ to $11.2 \%$, i.e., an increase of $5.6 \%$.

Tianjin, Tangshan, and four other cities with a large decline in environmental sustainability performed worse in terms of the optimization of the fossil energy structure (Table 6). The average proportion of $\mathrm{CO}_{2}$ emissions from coal in these six cities decreased by only $1.8 \%$, which was smaller than the average decline in the proportion of $\mathrm{CO}_{2}$ emissions from coal use in the $\mathrm{BTH}$ urban agglomeration (6.9\%). Except for Chengde, the proportion of $\mathrm{CO}_{2}$ emissions that were generated by the oil use of the six cities declined by $0.3 \%-4.6 \%$. In contrast, the same proportion increased by $1.2 \%$ in the urban agglomerations as a whole. The proportion of $\mathrm{CO}_{2}$ emissions that were generated by the natural gas use in these six cities increased by an average of only $2.6 \%$, while the overall proportion of the BTH urban agglomeration increased by $5.6 \%$.

In contrast, the proportion of $\mathrm{CO}_{2}$ emissions generated by coal use in Beijing, Handan, and the other five cities with lower environmental sustainability levels decreased by $12.0 \%$, and the proportion of $\mathrm{CO}_{2}$ emissions generated by oil and natural gas use increased by $5.7 \%$ and $6.3 \%$, respectively (Table 6). It can be seen that the decline of a city's environmental sustainability was smaller when the performance of the optimization of the fossil energy structure was better. Using Beijing and Tianjin as the examples, the optimization of the energy structure of the former was far better than that of the latter. In 2000, the proportions of $\mathrm{CO}_{2}$ emissions that were generated by coal use in Beijing and Tianjin were $80.2 \%$ and $77.7 \%$, respectively, i.e., they were basically at the same level. However, the proportion of $\mathrm{CO}_{2}$ emissions that were generated by coal use in 2005 in Beijing dropped to $25.7 \%$, representing a 
decline of $54.5 \%$, while the proportion of that in Tianjin dropped to $74.5 \%$, representing a decline of $3.1 \%$. In terms of the change in the proportion of $\mathrm{CO}_{2}$ emissions generated by natural gas use, Beijing increased by $31.7 \%$, which was also much greater than that in Tianjin (7.7\%). Therefore, Beijing, with a higher degree of optimization of the fossil energy structure, had a smaller decline in environmental sustainability than Tianjin.

Table 6. The changes in the percentage of per capita $\mathrm{CO}_{2}$ emissions from the three major fossil fuels in the Beijing-Tianjin-Hebei urban agglomeration.

\begin{tabular}{|c|c|c|c|c|c|c|c|c|c|c|}
\hline \multirow[b]{2}{*}{ Category } & \multirow[b]{2}{*}{ Region } & \multicolumn{3}{|c|}{ Coal Proportion } & \multicolumn{3}{|c|}{ Oil Proportion } & \multicolumn{3}{|c|}{ Natural Gas Proportion } \\
\hline & & 2000 & 2015 & $\begin{array}{l}\text { Rate of } \\
\text { Change }\end{array}$ & 2000 & 2015 & $\begin{array}{l}\text { Rate of } \\
\text { Change }\end{array}$ & 2000 & 2015 & $\begin{array}{l}\text { Rate of } \\
\text { Change }\end{array}$ \\
\hline \multirow{7}{*}{ First } & Tianjin & $77.7 \%$ & $74.5 \%$ & $-3.1 \%$ & $20.8 \%$ & $16.2 \%$ & $-4.6 \%$ & $1.5 \%$ & $9.3 \%$ & $7.7 \%$ \\
\hline & Chengde & $93.9 \%$ & $89.0 \%$ & $-4.9 \%$ & $5.5 \%$ & $8.3 \%$ & $2.9 \%$ & $0.6 \%$ & $2.7 \%$ & $2.0 \%$ \\
\hline & Cangzhou & $94.1 \%$ & $92.9 \%$ & $-1.2 \%$ & $5.2 \%$ & $5.0 \%$ & $-0.3 \%$ & $0.7 \%$ & $2.2 \%$ & $1.5 \%$ \\
\hline & Shijiazhuang & $93.8 \%$ & $92.5 \%$ & $-1.2 \%$ & $5.5 \%$ & $5.2 \%$ & $-0.2 \%$ & $0.8 \%$ & $2.2 \%$ & $1.5 \%$ \\
\hline & Langfang & $92.5 \%$ & $91.7 \%$ & $-0.8 \%$ & $6.9 \%$ & $6.0 \%$ & $-0.9 \%$ & $0.7 \%$ & $2.3 \%$ & $1.6 \%$ \\
\hline & Tangshan & $93.7 \%$ & $94.0 \%$ & $0.3 \%$ & $5.6 \%$ & $3.9 \%$ & $-1.6 \%$ & $0.8 \%$ & $2.1 \%$ & $1.3 \%$ \\
\hline & Average & $91.0 \%$ & $89.1 \%$ & $-1.8 \%$ & $8.3 \%$ & $7.4 \%$ & $-0.8 \%$ & $0.9 \%$ & $3.5 \%$ & $2.6 \%$ \\
\hline \multirow{8}{*}{ Second } & Beijing & $80.2 \%$ & $25.7 \%$ & $-54.5 \%$ & $17.2 \%$ & $40.3 \%$ & $23.2 \%$ & $2.6 \%$ & $34.0 \%$ & $31.4 \%$ \\
\hline & Qinhuangdao & $93.1 \%$ & $87.2 \%$ & $-5.9 \%$ & $6.2 \%$ & $9.5 \%$ & $3.3 \%$ & $0.7 \%$ & $3.3 \%$ & $2.6 \%$ \\
\hline & Zhangjiakou & $93.5 \%$ & $86.1 \%$ & $-7.4 \%$ & $5.8 \%$ & $10.8 \%$ & $5.0 \%$ & $0.7 \%$ & $3.1 \%$ & $2.4 \%$ \\
\hline & Hengshui & $94.5 \%$ & $88.8 \%$ & $-5.7 \%$ & $4.8 \%$ & $8.4 \%$ & $3.6 \%$ & $0.7 \%$ & $2.8 \%$ & $2.1 \%$ \\
\hline & Baoding & $93.4 \%$ & $88.7 \%$ & $-4.7 \%$ & $5.9 \%$ & $8.5 \%$ & $2.6 \%$ & $0.7 \%$ & $2.7 \%$ & $2.0 \%$ \\
\hline & Handan & $93.0 \%$ & $91.1 \%$ & $-1.9 \%$ & $6.3 \%$ & $6.3 \%$ & $0.0 \%$ & $0.7 \%$ & $2.6 \%$ & $1.9 \%$ \\
\hline & Xingtai & $94.0 \%$ & $89.8 \%$ & $-4.2 \%$ & $5.3 \%$ & $7.6 \%$ & $2.3 \%$ & $0.7 \%$ & $2.6 \%$ & $1.8 \%$ \\
\hline & Average & $91.7 \%$ & $79.6 \%$ & $-12.0 \%$ & $7.4 \%$ & $13.1 \%$ & $5.7 \%$ & $1.0 \%$ & $7.3 \%$ & $6.3 \%$ \\
\hline
\end{tabular}

Note: the classification of cities in this table is same as that in Table 4.

Optimizing the energy structure is one of the key factors in transforming the BTH urban agglomeration from a state of weak sustainability to a state of strong sustainability. The BTH agglomeration should focus on how to optimize the energy structure, improve the energy utilization efficiency, increase the proportion of clean energy, and adjust the industrial structure in terms of future emission reduction strategies [56]. At the same time, the government should buttress local low-carbon development, build specific guidelines and policy evaluation systems, summarize the practical experience, and share it [57].

\subsection{Future Perspectives}

This study evaluated the sustainability dynamics of 13 cities in the BTH urban agglomeration in the past 15 years from the three dimensions of society, economy, and the environment at the city scale. However, the study has some limitations. First, the accessibility of data limits the ability to calculate the HSDI at the city scale. We used the average life expectancy of Hebei Province instead of the actual data for each city when we calculated the LEI. Second, because the average life expectancy data for 2010 were used to replace the required data for 2015, the LEI values for 2015 might be smaller than the actual values.

In addition, the HSDI is still a weak sustainability index which does not consider the non-compensability and thresholds of each indicator [58]. Positive changes in the social and economic dimensions of sustainability can offset the degradation of the environmental dimension, which conforms to the belief that economic development at the cost of environmental degradation is sustainable [6]. In the future, a more comprehensive study regarding regional sustainability can be conducted by using both strong and weak sustainability indicators.

Moreover, carbon emission alone cannot fully capture the environmental dimension of sustainability. Previous studies have used normalized difference vegetation index (NDVI) data to calculate carbon sequestration $[59,60]$. By referring to the research of Hermosilla et al., high spatial resolution imagery and LiDAR data can be adopted to add street-based or block-based carbon 
sequestration into the environmental sustainability dimension, so as to measure the environmental sustainability of a city from two aspects of $\mathrm{CO}_{2}$ emission and sequestration, which can better reflect spatial heterogeneity and measure the sustainability differences between or within cities [61].

\section{Conclusions}

From 2000 to 2015, the overall sustainability of the BTH urban agglomeration showed an increasing trend, with an HSDI growth rate of $10 \%$. Among the three dimensions of sustainability, economic sustainability improved the most, while environmental sustainability declined. The change rates of the GDPI and EMI were $42 \%$ and $-8 \%$, respectively. The environmental sustainability of six cities, including Tianjin, Shijiazhuang, and Tangshan, decreased by 0.111 , which was $56.3 \%$ higher than the regional average.

The decline in environmental sustainability became an important factor limiting regional sustainable development. A significant positive correlation was found between changes in the regional EMI and HSDI, and the Pearson correlation coefficient reached $0.50(p<0.1)$. In contrast, the $H S D I$ was not significantly correlated with the LEI, EI, or GDPI. Urban energy structure optimization played an important role in affecting environmental sustainability. Among the six cities with regional average declines in environmental sustainability, the proportion of the $\mathrm{CO}_{2}$ emissions that were generated by coal use in the total $\mathrm{CO}_{2}$ emissions decreased by only $1.8 \%$, which was far smaller than the $12.0 \%$ decline that was observed in the other seven cities in the region. In the future, the development of the BTH urban agglomeration should focus on improving environmental sustainability while achieving economic development. Optimizing the energy structure in the region will be a powerful path for building a resource-saving and environmentally friendly society.

Author Contributions: Conceptualization, Methodology, Formal Analysis, S.C. and Q.H.; Software, S.C.; Validation, S.C.; Writing-Review \& Editing, S.C., Q.H., Z.L., S.M., D.Y., L.Z. and C.H.

Funding: This research was supported in part by the Beijing Nova Program (Grant No. Z181100006218049) and the Beijing Natural Science Foundation (Grant No. 8192027).

Acknowledgments: We express our gratitude to anonymous reviewers and editors for their professional comments and suggestions.

Conflicts of Interest: The authors declare no conflict of interest. The sponsors had no role in the design, execution, interpretation, or writing of the study.

\section{References}

1. Ness, B.; Urbel-Piirsalu, E.; Anderberg, S.; Olsson, L. Categorising tools for sustainability assessment. Ecol. Econ. 2007, 60, 498-508. [CrossRef]

2. Wu, J.G.; Guo, X.C.; Yang, J.; Qian, G.; Niu, J.; Liang, C.; Zhang, Q.; Li, A. What is sustainability science? Chin. J. Appl. Ecol. 2014, 25, 1-11. [CrossRef]

3. Wu, J.G.; Wu, T. Sustainability indicators and indices: An overview. In Handbook of Sustainability Management; Pace University: New York, NY, USA, 2012; pp. 65-73.

4. Devuyst, D.; Hens, L.; de Lannoy, W. How Green Is the City? Sustainability Assessment and the Management of Urban Environments; Columbia University Press: New York, NY, USA, 2001. [CrossRef]

5. $\mathrm{Wu}, \mathrm{J}$. Landscape sustainability science: Ecosystem services and human well-being in changing landscapes. Landsc. Ecol. 2013, 28. [CrossRef]

6. Shang, C.W.; Wu, T.; Huang, G.L.; Wu, J.G. Weak sustainability is not sustainable: Socioeconomic and environmental assessment of Inner Mongolia for the past three decades. Resour. Conserv. Recycl. 2019, 141, 243-252. [CrossRef]

7. Huang, G.L.; Jiang, Y.Q. Urbanization and Socioeconomic Development in Inner Mongolia in 2000 and 2010: A GIS Analysis. Sustainability 2017, 9, 235. [CrossRef]

8. Kuei, C. (Ed.) Handbook of Sustainable Management; Imperial College Press: London, UK, 2006; pp. 65-86. 
9. Daly, H.; Jacobs, M.; Skolimowski, H. Discussion of beckerman's critique of sustainable development. Environ. Values 1995, 4, 49-70. [CrossRef]

10. Daly, H.E. Georgescu-roegen versus solow/stiglitz. Ecol. Econ. 1997, 22, 267-268. [CrossRef]

11. Adams, W.M. The future of sustainability: Re-thinking environment and development in the twenty-first century. In Report of the IUCN Renowned Thinkers Meeting; Springer: Dordrecht, Netherlands, 2006; Volume 29, p. 31. Available online: https://link.springer.com/book/10.1007/1-4020-4908-0 (accessed on 28 May 2019).

12. Shaker, R.R. A mega-index for the Americas and its underlying sustainable development correlations. Ecol. Indic. 2018, 89, 466-479. [CrossRef]

13. Human Development Reports. Available online: http://hdr.undp.org/en/content/human-development-indexhdi (accessed on 28 May 2019).

14. Happy Planet Index. Available online: http://happyplanetindex.org/about (accessed on 28 May 2019).

15. Shields, K.; Langer, H.; Watson, J.; Stelzner, K. European Green City Index: Assessing the environmental impact of Europe's Major Cities; Siemens AG: Munich, Germany, 2019. Available online: https://www.osti.gov/etdeweb/ biblio/21274792 (accessed on 28 May 2019).

16. Togtokh, C.; Gaffney, O. Human Sustainable Development Index [EB/OL]. In Web-Magazine of the United Nations University; United Nations University: Tokyo, Japan, 2010; Available online: https://ourworld.unu. edu/en/the-2010-human-sustainable-development-index (accessed on 28 May 2019).

17. UN-Habitat. Global Urban Indicators Database Version 2; United Nations Human Settlements Programme; Global Urban Observatory: Nairobi, Kenya, 2002.

18. Sustainable Society Index-Your Compass to Sustainability. Available online: http://www.ssfindex.com (accessed on 28 May 2019).

19. Huang, L.; Wu, J.G.; Yan, L.J. Defining and measuring urban sustainability: A review of indicators. Landsc. Ecol. 2015, 30, 1175-1193. [CrossRef]

20. Yang, Y.H.; Hu, A.G. Investigating Regional Disparities of China's Human Development with Cluster Analysis: A Historical Perspective. Soc. Indic. Res. 2008, 86, 417-432. [CrossRef]

21. Theng, Y.L.; Xu, X.; Kanokkorn, W. Towards the Construction of Smart City Index for Analytics (SM-CIA): Pilot-Testing with Major Cities in China Using Publicly Available Data. In Proceedings of the 2016 49th Hawaii International Conference on System Sciences (HICSS), Koloa, HI, USA, 5-8 January 2016; pp. 2964-2973. [CrossRef]

22. Yu, Y.; Yu, M.; Lin, L.; Chen, J.; Li, D.; Zhang, W.; Cao, K. National Green GDP Assessment and Prediction for China Based on a CA-Markov Land Use Simulation Model. Sustainability 2019, 11, 576. [CrossRef]

23. Sun, C.Z.; Tong, Y.L.; Zou, W. The evolution and a temporal-spatial difference analysis of green development in China. Sustain. Cities Soc. 2018, 41, 52-61. [CrossRef]

24. Gao, Y.; Li, S.; Li, Y.; Li, S.C. Freshwater ecosystem service footprint model: A model to evaluate regional freshwater sustainable development-A case study in Beijing-Tianjin-Hebei, China. Ecol. Indic. 2014, 39, 1-9. [CrossRef]

25. Peng, J.; Du, Y.; Ma, J.; Liu, Z.; Liu, Y.; Wei, H. Sustainability evaluation of natural capital utilization based on 3D EF model: A case study in Beijing City, China. Ecol. Indic. 2015, 58, 254-266. [CrossRef]

26. Huang, L.; Yan, L.J.; Wu, J.G. Assessing urban sustainability of Chinese megacities: 35 years after the economic reform and open-door policy. Landsc. Urban Plan. 2016, 145, 57-70. [CrossRef]

27. UNDP. Human Development Report 2010. Available online: http://hdr.undp.org/sites/default/files/reports/ 270/hdr_2010_en_complete_reprint.pdf (accessed on 28 May 2019).

28. Li, J.W.; Liu, Z.F.; He, C.Y.; Gao, B. Assessing the Human-environment System Sustainability in China from 1990 to 2010 Based on Human Sustainable Development Index. J. Nat. Resour. 2015, 30, 1118-1128. [CrossRef]

29. Lu, D.D. Function orientation and coordinating development of subregions within the Jing-Jin-Ji Urban Agglomeration. Prog. Geogr. 2015, 34, 265-270. [CrossRef]

30. Fang, C.L.; Song, J.T.; Zhang, Q.; Li, M. The formation, development and spatial heterogeneity patterns for the structures system of urban agglomerations in China. Acta Geogr. Sin. 2005, 827-840. [CrossRef]

31. National Bureau of Statistics. China Statistical Yearbook 2018; China Statistics Press: Beijing, China, 2018.

32. Tao, Y.; Li, F.; Crittenden, J.C.; Lu, Z.; Sun, X. Environmental Impacts of China's Urbanization from 2000 to 2010 and Management Implications. Environ. Manag. 2016, 57, 498-507. [CrossRef]

33. Chu, X.; Deng, X.Z.; Jin, G.; Wang, Z.; Li, Z.H. Ecological security assessment based on ecological footprint approach in Beijing-Tianjin-Hebei region, China. Phys. Chem. Earth 2017. [CrossRef] 
34. National Bureau of Statistics. China City Statistical Yearbook 2001; China Statistics Press: Beijing, China, 2001.

35. National Bureau of Statistics. China City Statistical Yearbook 2016; China Statistics Press: Beijing, China, 2016.

36. Beijing Municipal Bureau of Statistics. Beijing Statistical Yearbook 2001; China Statistics Press: Beijing, China, 2001.

37. Beijing Municipal Bureau of Statistics. China City Statistical Yearbook 2016; China Statistics Press: Beijing, China, 2016.

38. Tianjin Municipal Bureau of Statistics. Tianjin Statistical Yearbook 2001; China Statistics Press: Tianjin, China, 2001.

39. Tianjin Municipal Bureau of Statistics. TianjinStatistical Yearbook 2016; China Statistics Press: Tianjin, China, 2016.

40. The People's Government of Hebei Province. Hebei Economic Yearbook 2001; China Statistics Press: Beijing, China, 2001.

41. The People's Government of Hebei Province. Hebei Economic Yearbook 2016; China Statistics Press: Beijing, China, 2016.

42. National Bureau of Statistics. China Energy Statistical Yearbook 2001; China Statistics Press: Beijing, China, 2001.

43. National Bureau of Statistics. China Energy Statistical Yearbook 2016; China Statistics Press: Beijing, China, 2016.

44. Morse, S.; Mcnamara, N.; Acholo, M.; Okwoli, B. Sustainability indicators: The problem of integration. Sustain. Dev. 2001, 9, 15. [CrossRef]

45. Togtokh, C. Time to stop celebrating the polluters. Nature 2011, 479, 269. Available online: https: //www.nature.com/news/time-to-stop-celebrating-the-polluters-1.9370 (accessed on 28 May 2019). [CrossRef] [PubMed]

46. Bravo, G. The Human Sustainable Development Index: New calculations and a first critical analysis. Ecol. Indic. 2014, 37, 45-150. [CrossRef]

47. IPCC (Intergovernmental Panel on Climate Change). IPCC Guidelines for National Greenhouse Gas Inventories: Volume 2 [EB/OL]. Available online: http://www.ipcc-nggip.iges.or.jp/public/2006gl/vol2.html (accessed on 28 May 2019).

48. World Resources Institute. 2013 Greenhouse Gas Accounting Tool for Chinese Cities (Pilot Version 1.0). Available online: http:/www.wri.org.cn/sites/default/files/GHG\%20Accounting\%20Tool\%20for\%20Chinese \% 20Cities.pdf (accessed on 28 May 2019).

49. Jing, Q.N.; Luo, W.; Bai, H.T.; Xu, H. A method for city-level energy-related $\mathrm{CO}_{2}$ emission estimation. Acta Sci. Circumstantiae 2018, 38, 4879-4886. [CrossRef]

50. Yim, O.; Ramdeen, K.T. Hierarchical cluster analysis: Comparison of three linkage measures and application to psychological data. Quant. methods Psychol. 2015, 11, 8-21. [CrossRef]

51. Bratchell, N. Cluster analysis. Chemom. Intell. Lab. Syst. 1989, 6, 105-125. [CrossRef]

52. Carter, R.L.; Morris, R.; Blashfield, R.K. On the partitioning of squared Euclidean distance and its applications in cluster analysis. Psychometrika 1989, 54, 9-23. [CrossRef]

53. Sprent, P.; Smeeton, N.C. Applied nonparametric statistical methods. Chapman Hall/CRC 2010. [CrossRef]

54. IBM Corporation 1989. IBM SPSS Statistics 24 Command Syntax Reference; Routledge: London, UK, 2016.

55. Su, Y.Y.; Chen, X.Z.; Ye, Y.Y.; Wu, Q.T.; Zhang, H.O.; Huang, N.S.; Kuang, Y.Q. The characteristics and mechanisms of carbon emissions from energy consumption in China using DMSP/OLS night light imageries. Acta Geogr. Sin. 2013, 11, 1513-1526.

56. Ou, X.M.; Yuan, Z.Y.; Peng, T.D.; Sun, Z.Q.; Zhou, S. The Low-Carbon Transition toward Sustainability of Regional Coal-Dominated Energy Consumption Structure: A Case of Hebei Province in China. Sustainability 2017, 9, 1184. [CrossRef]

57. Li, H.M.; Wang, J.; Yang, X.; Wang, Y.F.; Wu, T. A Holistic Overview of the Progress of China's Low-Carbon City Pilots. Sustain. Cities Soc. 2018, 42, 289-300. [CrossRef]

58. Gan, X.; Fernandez, I.C.; Guo, J.; Wilson, M.; Zhao, Y.; Zhou, B.; Wu, J. When to use what: Methods for weighting and aggregating sustainability indicators. Ecol. Indic. 2017, 81, 491-502. [CrossRef]

59. Zu, W.Q.; Pan, Y.Z.; Zhang, J.S. Estimation of net primary productivity of Chinese terrestrial vegetation based on remote sensing. J. Plant Ecol. 2007, 31, 413-424. [CrossRef] 
60. Meng, S.T.; Huang, Q.X.; He, C.Y.; Yang, S.S.M. Mapping the Changes in Supply and Demand of Carbon Sequestration Service: A Case Study in Beijing. J. Nat. Resour. 2018, 33, 1191-1203. [CrossRef]

61. Hermosilla, T.; Palomar-Vázquez, J.; Balaguer-Beser, Á.; Balsa-Barreiro, J.; Ruiz, L.A. Using street based metrics to characterize urban typologies. Comput. Environ. Urban Syst. 2014, 44, 68-79. [CrossRef]

(C) 2019 by the authors. Licensee MDPI, Basel, Switzerland. This article is an open access article distributed under the terms and conditions of the Creative Commons Attribution (CC BY) license (http://creativecommons.org/licenses/by/4.0/). 